\title{
COLLOCATIONAL KNOWLEDGE UPTAKE BY UNIVERSITY STUDENTS UNDER ONLINE LEARNING
}

\author{
Svetlana Danilina \\ Taras Shevchenko National University of Kyiv, Ukraine
}

\begin{abstract}
Check for updates

The article discusses an experiment that looked into the acquisition of collocational knowledge in three university groups studying online, each subjected to different learning conditions: incidental acquisition, intentional acquisition, and intentional acquisition with an extra productive output (essay), the latter having been assessed for the amount and accuracy of target lexis usage in their texts. The aim of the study was to see how well upper-intermediate university students could identify collocations in an input text, and how the text-based output affected the collocational uptake outcomes. The study showed that the productive output group outperformed the other intentional learning group, while incidental acquisition group failed to complete a productive knowledge posttest. Although the study revealed only slightly higher gains in the output group, their results appeared more consistent than those demonstrated by the other intentional uptake group, whose retention rate decreased by the time of delayed posttest.
\end{abstract}

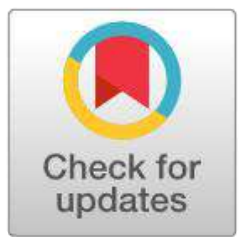

Keywords: collocational knowledge, ESP, vocabulary uptake, involvement load, written output

\section{Article history:}

Received: 11 January 2021;

Reviewed: 14 January 2021;

Revised: 18 March 2021;

Accepted: 1 May 2021;

Published: 1 June 2021

Copyright (C) 2021 Svetlana Danilina

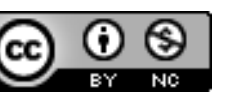

This open access article is published and distributed under a CC BY-NC 4.0 International License which permits non-commercial use, distribution, and reproduction in any medium, provided the original author and source are credited. Permissions beyond the scope of this license may be available at sv.danilina@gmail.com. If you want to use the work commercially, you must first get the authors' permission.

Citation: Danilina, S. (2021). Collocational Knowledge Uptake by University Students under Online Learning. English Studies at NBU, 7(1), 97-117. https://doi.org/10.33919/esnbu.21.1.7

Svetlana Danilina, PhD, is an Associate Professor of the Department of Foreign Languages for Faculties of Philosophy and History at Taras Shevchenko National University of Kyiv, Ukraine. She teaches General English and ESP courses to undergraduate students of history and philosophy. Her research interests focus on various aspects of second language acquisition, including the use of communicative approach and CLIL methodology in teaching ESP in university settings, intentional and incidental vocabulary uptake, and literary translation and the applicability of translation in the contemporary EFL classroom.

E-mail: sv.danilina@gmail.com

https://orcid.org/0000-0002-2005-9363 


\section{Acquisition of Formulaic Language}

It is obvious to both teachers and learners of a foreign language that the mastery of L2 vocabulary is impossible without solid command of formulaic language, therefore the importance of acquiring vocabulary in chunks and attending to the collocability of lexical units has been a cornerstone of the communicative approach to L2 teaching.

Formulaic sequences or multi-word units are split into several categories, which traditionally include idioms, commonplace quotations, phrasal verbs, and collocations. Fernandez and Schmitt (2015) suggest the following definition of collocation: 'the tendency of two or more words to co-occur in discourse' (p. 95). Collocation is approached differently by phraseology and corpus linguistics, the former viewing it as a combination of words with a different degree of fixedness, whereas the latter identifies collocations based on statistical calculation and frequency of the co-occurrence of the elements of a collocation (Adamcova, 2020). Thus, although originally collocation was viewed by Firth (1968) as a purely textual phenomenon, later corpus linguists who adhere to 'neo-Firthian' tradition have given the notion a psychological interpretation. Sinclair (1991, p. 110), for example, sees collocation as 'a number of semipreconstructed phrases that constitute single choices, even though they might appear to be analyzable into segments available to the speaker'. For Ellis (2003) collocation is a linguistic phenomenon associated with chunking, viewed as a common learning mechanism. Hoey's (2012, p. 1) lexical priming theory views collocation as 'the product of drawing upon a mental store of lexical combinations'. Regardless of the approach taken, collocation is universally defined as a set sequence of words, which - if altered deprives linguistic output of fluency and idiomaticity.

\section{Literature Review}

Previously understudied in phraseology, lately the concept of collocation has been gaining popularity (Adamcova, 2020), and discussion as for the acquisition of formulaic knowledge by language learners has been held by methodologists and linguists alongside traditional research into vocabulary uptake. Despite a growing number of publications looking into the subject, there still seem to be more questions than answers once it comes to the specificity of acquiring formulaic knowledge depending on the source of such vocabulary, the acquisition of collocations from 
professional input materials in the academic setting, the difference in the learning gains depending on the mode of learning (intentional vs incidental), the factors which impact the efficiency of the uptake, etc.

Although the communicative theory of second language acquisition emphasizes learning vocabulary in chunks or collocations to promote speaking fluency and idiomaticity, in a way similar to a child acquiring their first language, formulaic sequences remain notoriously difficult for learners, especially in productive use (Snoder, 2017). In his Lexical Approach, Michael Lewis (1999) cites the ability to 'chunk' language as 'a central element of language teaching' (p.vi), similarly, Nick Ellis (2003) maintains that chunking is a basic associative learning process and a ubiquitous feature of human memory. Lewis (2000) foregrounds the skill of noticing collocations in input texts, however other studies argue that it does not seem to yield enhanced learning outcomes (Boers \& Lindstromberg, 2012). The scholars also question Lewis's overreliance on learners' ability to identify and learn collocations on their own (Boers \& Lindstromberg, 2009). Alison Wray (2002) argues that adult L2 learners are bound to resort to an essentially non-formulaic approach to language learning. Their analytic treatment of the language, largely caused by their ability to write in a language, gets them to perceive individual words as separate entities. This in its turn leads to the commonplace way of second language acquisition in vocabulary and grammar mode, which can hardly be changed.

A number of studies into factors behind the efficiency of the formulaic language acquisition have been conducted by Norbert Schmitt and his colleagues. Fernandez and Schmitt (2015, p.100) maintain there is a tendency of 'higher frequency leading to a greater chance of learning phrasal verbs to a productive degree of mastery'. Garnier and Schmitt (2016) view corpus frequency as the main predictor of knowledge of phrasals, while the rest of pre-requisites including a student's year of studies, their immersion in L2 environment, and semantic opacity of the phrasal are dismissed. These results are in line with the research conducted by Ellis et al. (2008), which showed that processing of formulaic language in non-native speakers is frequency sensitive, while native speakers are attuned to MI (mutual information, or the degree of the formula fixedness). 
As for collocations, González Fernández and Schmitt (2015) found only a relatively weak link between frequency of occurrence in input materials and their productive knowledge, and concluded that frequency cannot be used as the major predictor of collocation learning. This correlates with Durrant's (2014) analysis of nineteen collocation studies, which found that frequency was only modestly responsible for the collocation uptake. According to Gonzalez and Schmitt (2015), the success in mastering formulaic sequences is more dependent on the amount of meaningful language use and informal exposure to the target language that engages learners in everyday communicative situations (reading, watching TV or films, social networking, etc.). The results are supported by the study done by Macis and Schmitt (2017), which suggests the importance of students' engagement for learning gains, and Schmitt, who points out that 'students' motivation and attitude matter, as even the best materials are no good if students don't engage with them', and that 'there is an effect of students' strategic behavior [...] where one's self-regulation of learning leads to more involvement with and use of vocabulary learning strategies, which in turn leads to a better mastery of their use' (Schmitt, 2008, p. 338) .

The hypothesis of involvement importance has been supported by the research conducted by Reuterskiöld and Van Lancker Sidtis (2012), who explored comprehension and retention of L1 idioms by 9-14-year-old girls from a single spoken exposure in a natural interactive context. High rates of the accurate recognition and comprehension of the target idioms suggest a special relationship that formulaic expressions have to linguistic and social context, 'since the meaning of an idiom as a holistic unit is more strongly linked to the non-linguistic context than to the meaning of the individual linguistic components' (Reuterskiöld \& Van Lancker Sidtis, 2012, p.16). It might be concluded that learners subjected to greater amounts of meaningful interaction will likely learn more formulaic sequences, as formulas can be viewed as 'consolidation of a specific, concrete explicit memory', which later become 'more schematic linguistic constructions' integrated into the system by implicit learning during subsequent input processing (Ellis, 2005, p. 320). The above findings are in line with Laufer and Hulstijn's (2001) hypothesis that draws attention to the need for vocabulary activities to promote depth of processing, by demanding learner involvement. 
Meanwhile, an important limitation pointed out by Schmitt and Macis (2012) is that most L2 collocation studies to date have mainly focused on collocations with literal meanings, not figurative formulaic sequences. Therefore, it is still an open question to what degree the previous findings about frequency also apply to figurative collocations.

As for the results of intentional vocabulary uptake comparable with our experiment it is worth quoting Paul Pauwels (2018), who cites the outcomes of a number of experiments into intentional word acquisition, according to which the retention rate varies from about $25 \%$ on passive recall to about $52 \%$ of target lexis on passive recognition (Laufer \& Rozovski-Roitblat, 2011), to the retention rates of over $70 \%$ in the research by Laufer and Fitzpatrick into intentional (word list) learning (Laufer 2005; Fitzpatrick et al., 2008). The limitations of the above studies in respect to our experiment is that primarily all of them targeted single words rather than collocations, and secondly final posttests to check the amount of retention were administered in various formats and over different time spans from the moment of initial lexis introduction.

A study into incidental vocabulary retention was conducted by Nguyen and Boers (2018), who discuss the outcomes of content-focused activities in the inputoutput-input sequence based on a video recording serving as an input text. According to the experiment results, which featured incidental vocabulary uptake, the summary group demonstrated twice better retention rates compared to comparison group ( $44.44 \%$ vs $22.22 \%$ ) or 8 out of 18 target words vs 4 words. It should be noted though that the above retention rates have been demonstrated in single word learning procedures. The authors observe that although the difference between intentional and incidental learning is not always straightforward, the former can be emphasized by an explicit task given to the students to use the vocabulary presented in some practical activities of their own.

When it comes to the intentional learning of collocations, some previous research has proved its effectiveness (Peters, 2014, 2016), but relatively little is known about the outcomes of incidental acquisition of L2 collocations, with a number of factors viewed as essential predictors of collocational knowledge by some studies and dismissed as such by others (Garnier \& Schmitt, 2016). Ana Pellicer-Sanchez (2017) 
looked into the incidental acquisition of collocational knowledge from reading input. The research demonstrated that collocational knowledge is gained at a similar rate to the form and meaning of individual words. Incidental uptake of formulaic sequences from audio-visual input was in the focus of attention of Eva Puimege and Elke Peters (2019), who revealed a positive relationship between learners' prior vocabulary knowledge and the learning gains, while the strongest predictor of learning the form of formulaic sequences was established to be the pre-knowledge of the meaning of such formulas. At the same time, according to scholars (Pellicer-Sanchez, 2017; Szudarski, 2017), research into incidental uptake of L2 collocations is still relatively scarce, and the limited empirical evidence available now leaves a lot of questions unanswered as for the factors affecting their incidental acquisition.

The present study draws on Laufer and Hulstijn's hypothesis of task-induced involvement (or involvement load hypothesis) (Hulstijn \& Laufer, 2001), which suggests three components of engagement that act as predictors of vocabulary uptake from a text-need, search, and evaluation. Both groups subjected to the experiment felt either an artificially created need (when learners had to find collocations in the article stimulated by their first translation task), or actual need of students (when they had to find collocations they would want to use in their essays); the tasks also prompted the learners to search for the vocabulary pieces in the input article to fill in the lexical lacunae they detected when trying to express their ideas; Group 2 students supposedly also had to evaluate the accuracy of their essays against the input text (Nguyen \& Boers, 2018). Thus, the objective of this paper is primarily to assess the efficiency of collocational uptake by university students in two instances of intentional acquisition, which at the same time differ in the nature of their need component, and one of the groups being subjected to the evaluation element of the involvement load triad. It also aims to examine how additional productive output influenced the learning outcomes; and analyse what factors may have affected the target vocabulary uptake. A sub-aim of the study is to see how well upper-intermediate university students can identify collocations in an input text, and to assess the accuracy of the actual usage of the target lexis in Group 2 students' written output.

Our study is different from the available research in the following aspects: the object of study (we compare two ways of intentional acquisition of collocations in the 
academic setting and look into the outcomes of collocation retention (productive form recall) after two weeks from the date of the initial encounter, and then after a month from the date of the first posttest); assessing the actual accuracy of the target lexis usage in the students' written output; the mode of learning, as the experiment occurred under the online mode of instruction due to the covid-19 pandemic. Initially it was also planned to compare the scope of collocational uptake in intentional vs incidental acquisition groups, in the course of the experiment though this part had to be cancelled.

\section{Method}

All the classes described below were conducted via Zoom application during the covid-19 lockdown in the spring of 2020. The tasks featured in the experiment in Groups 1 and 2 were part of their regular studies plan, while Group 3 students were asked to volunteer to participate in the study. Groups 1 and 2 are first-year students at the Faculties of History and Philosophy, who have a B1+/B2 level of English. After they completed the posttests, Group 2 students were informed about the intention to use quotations from their essays and results of their tests for the purpose of writing this article, without disclosing any of their names, to which they gave their oral consent. Group 3 are third-year students at the Faculty of Philosophy at B1+/B2 taking an English for Specific Purposes (ESP) course. Group 3 learners participated in the experiment on a voluntary basis in extracurricular online sessions and were aware of the fact that their participation would not affect their semester score.

A quantitative method was employed to calculate the number of lexical items used in the written output and later recalled in posttests. A qualitative method was applied to analyze the accuracy of the learners' productive output.

\section{Participants}

Group 1 consisted of 14 students altogether, while Group 2 of 15; and Group 3 of 18; the total of 29 students took part in the experiment ( 6 of Group 1; 12 of Group 2; 11 of Group 3), which equals the number of students who sent in their essays and wrote posttests, with female students prevailing (5/6 in Group 1; 7/12 in Group 2, 8/11 in Group 3). 


\section{Group 1}

Group 1 students wrote an essay on the prospects of higher education under new circumstances, and over the following week they were given feedback on the essays via email. The subject was selected due to its topicality at the time of conducting the experiment to enhance the students' involvement with the task and provide them with an opportunity of meaningful engagement with L2 in their classroom activities. In the next class they read an article on the same subject and were asked to find the collocations that could have been useful for them in writing the essay. The text was a part of the article Is online learning the future of education? ${ }^{1}$, which had been abridged for the purpose of classroom usage. Then the students compared the lists of their collocations and did some gap fill exercises. Because the group had initially been planned for incidental uptake experiment, the learners were neither asked explicitly to memorize the lexis, nor warned of the forthcoming test. After two weeks they were offered a translation task based on the detected collocations. The sentences did not offer any necessities for translation transformations and could be translated into L2 mostly keeping the L1 grammar structures, the focus there was on identifying the target lexical items. Only 6 students out of the group's 14 completed the task, with absolute majority of the target collocations unidentified.

Initially, it had been planned to conduct a second posttest in this group a month later but after the first test it became clear the initial plan would not make sense, as the students seemed quite reluctant to participate and the test outcomes turned out rather poor.

The study therefore concentrated on revealing the difference in the learning gains between Group 2 and Group 3 subjected to intentional mode of acquisition. The groups were different in their need component: an actual need of Group 2 students which arose in the course of their essay writing, and an artificially created need of Group 3 stimulated by the initial test they were offered. The experiment also aimed at examining the impact that the additional productive output (essay writing) had on the learning outcomes in Group 2, which gave the group an extra opportunity of the target lexis evaluation.

\footnotetext{
${ }^{1}$ https://www.weforum.org/agenda/2016/09/is-online-learning-the-future-of-education
} 


\section{Group 2}

Twelve students out of the group's 15 participated in the study. In the first class the learners were offered the same article as Group 1, in which they had to identify collocations. After their suggestions had been put forward, the whole group discussed various kinds of formulaic language, and the students were offered a final list of the target collocations. As homework the learners were asked to write a 250-300 word essay on the online prospects of higher education. They had to use as many target collocations as they could in their essays. Thirteen students sent in their essays, although just 11 used at least one target lexical item, and one essay was a copy-paste from the internet. The author of this text was not included into the final results analysis. Over the course of the next two weeks the essays were received from the group and feedback was sent to them on the accuracy of their collocational usage. In the class following the essay submission deadline, the students took a module test assessing their target lexis recall through offering them sentences in Ukrainian containing target collocations which they had to translate into English. The test was similar to the one offered to Group 1 and did not call for any complex translation solutions. The test addressed the learners' productive form recall of the target lexis. The students had been warned about the test; therefore, their mode of learning was intentional. The second posttest was conducted after about a month from the date of the first posttest. It aimed to see change in the amount of recall. The second (delayed) posttest was done in a listformat with target collocations given in Ukrainian and a task to render them into English. The translation format was chosen deliberately to streamline the learners' recall task without supplying them with any L2 cues, like initial letters of target collocations. The items in posttest 2 were listed in a sequence different from the sentence-based posttest 1 .

\section{Group 3}

Eleven third year students out of the group's 18 volunteered to participate in the experiment. In the initial stage the learners were asked to do a translation test, which was sent to them by email. The test, the same as the one given to Groups 1 and 2, consisted of sentences in Ukrainian which called for the target collocations to be used in their English translation. This stage was supposed to have the learners feel the lacunae in their vocabulary stock and create an artificial need for the lexis they might be missing. 
The only target expressions the learners came up with were "in (the) face of" (4 students) and "achieve an aim" (3 students). After that, in a zoom session, they had to find the target collocations in the offered article, which turned out quite easy for them to do. They were asked to memorize the target vocabulary in any way that they usually do, and after 14 days from visiting the article the students were asked to do a list based posttest where they were given the target phrases in Ukrainian and they had to reproduce their meaning in English. They took another identical posttest a month from the first one, with the items given in a different sequence. Ten students out of the eleven who had initially agreed to participate in the study did the test at home and sent their results by email. Because the learners were explicitly asked to memorize the target vocabulary and were aware of the test dates, their mode of learning was intentional.

\section{Results}

The main aim of our experiment was to research and assess the perception, internalization, and application of collocations by B1+/B2 ESP students of a Ukrainian university. First-year students took part in the experiment as part of their English language syllabus, while third-year students participated in the experiment on a good will basis. A sub-aim of the study was evaluating upper-intermediate learners' skill of identifying L2 collocations in an input text.

Group 2 and Group 3 turned out to have different recall rates per collocation. Whereas Group 3's delayed posttest top recalled units were dire need, in face of, and prospective students (recalled by $90-100 \%$ of students), Group 2's top recalled was prospective students (92\%), followed by in face of, tertiary education, and achieve an aim (75\%). The item least recalled in the delayed posttest by both groups was make great strides (recalled by only 34\% of Group 2 as a full unit with the right adjective, and only by one student in Group 3, who recalled its form as 'make a great strides'). The final learning gains in Group 2 appear to have no direct relation to the usage rate of a corresponding collocation in the learners' essays (difference in the recall rate vs usage rate can amount to $40 \%$ in the case of in face of), while the final results of Group 2 and 3 generally are more consistent with the uptake both groups demonstrated in their first posttest (the recall rate stays on average within $10 \%$ fluctuation between the posttests). 
At the same time, the gains demonstrated by Group 3 are characterized by extreme values, unlike those of Group 2: two items (dire need, in face of) were recalled by all Group 3 students, while the least remembered item by just $10 \%$ of the students vs $92 \%$ and $34 \%$ rate respectively for Group 2 . Table 1 summarizes the results demonstrated by the students in the conducted tests and the written output.

\section{Table 1}

Group 2 \& 3's Summarized Learning Outcomes

\begin{tabular}{|l|l|l|l|l|l|}
\hline Collocation & \multicolumn{4}{|l|}{$\begin{array}{l}\text { Group 2 } \\
\text { times recalled (used)/total Sts }\end{array}$} & $\begin{array}{l}\text { Group 3 } \\
\text { times recalled /total Sts }\end{array}$ \\
\hline & Essay & Posttest 1 & Posttest 2 & Posttest 1 & Posttest 2** \\
\hline Dire need & $50 \%$ & $75 \%$ & $67 \%$ & $100 \%$ & $100 \%$ \\
& $(6 / 12)$ & $(9 / 12)$ & $(8 / 12)$ & $(11 / 11)$ & $(10 / 10)$ \\
\hline In face of & $34 \%$ & $75 \%$ & $75 \%$ & $100 \%$ & $100 \%$ \\
& $(4 / 12)$ & $(9 / 12)$ & $(9 / 12)$ & $(11 / 11)$ & $(10 / 10)$ \\
\hline $\begin{array}{l}\text { Tertiary } \\
\text { education }\end{array}$ & $84 \%$ & $67 \%$ & $75 \%$ & $55 \%$ & $40 \%$ \\
\hline Make good on & $(10 / 12)$ & $(8 / 12)$ & $(9 / 12)$ & $(6 / 11)$ & $(4 / 10)$ \\
\hline Achieve an aim & $(2 / 12)$ & $50 \%$ & $42 \%$ & $27 \%$ & $20 \%$ \\
& $(5 / 12)$ & $(6 / 12)$ & $(5 / 12)$ & $(3 / 11)$ & $(2 / 10)$ \\
\hline $\begin{array}{l}\text { Prospective } \\
\text { students }\end{array}$ & $58 \%$ & $75 \%$ & $75 \%$ & $81 \%$ & $70 \%$ \\
\hline $\begin{array}{l}\text { Traditional } \\
\text { classroom }\end{array}$ & $(7 / 12)$ & $67 \%$ & $(9 / 12)$ & $(9 / 11)$ & $(7 / 10)$ \\
features & $50 \%$ & $(8 / 12)$ & $(11 / 12)$ & $(9 / 11)$ & $90 \%$ \\
\hline Make strides & $(6 / 12)$ & $(4 / 12)$ & $(6 / 12)$ & $6 / 10)$ \\
\hline $\begin{array}{l}\text { (Make) great } \\
\text { strides* }\end{array}$ & $75 \%$ & $75 \%$ & $50 \%$ & $3 / 11)$ & $40 \%$ \\
\hline $\begin{array}{l}\text { Insurmountabl } \\
\text { e obstacle }\end{array}$ & $(9 / 12)$ & $(9 / 12)$ & $(6 / 12)$ & $(4 / 11)$ & $(3 / 10)$ \\
\hline
\end{tabular}

Note: *Due to frequent usage of 'make strides' instead of 'make great strides' it was decided to split this idiom into two for final analysis, as both forms of the idiom are defined as correct by dictionaries.

** Results are calculated for the ten students who participated in the second posttest, not the eleven students who had initially participated in the experiment.

***The collocation form was recalled as "make a great strides".

A more detailed target collocations usage in the students' written output is displayed in Table 2. On average the learners managed to integrate over a half of the vocabulary into their essays (5.3 collocations out of 10$)$. The most frequently encountered vocabulary items were tertiary education used by 11 out of the 12 students (92\%) and make great strides by 10 out of 12 (84\%), the least popular lexical item was make good on 
used by only 2 learners (17\%). The expressions which featured on top of the usage list were also those used mostly incorrectly: make great strides and make good on.

Table 2

Target collocation usage in written output by Group 2

\begin{tabular}{|l|l|}
\hline Vocabulary aspects & Written Output \\
\hline Students who used at least one expression & $11 / 12$ \\
\hline The average number of expressions used per students & $5.3 / 10$ \\
\hline Mostly incorrectly & $\begin{array}{l}\text { make great strides }(2 / 9) ; \\
\text { in the face of }(1 / 4) ; \\
\text { make good on }(1 / 2)\end{array}$ \\
\hline The highest scored student & $10 / 10$ \\
\hline The least scored student & $3 / 10$ \\
\hline The most frequently used & $\begin{array}{l}\text { tertiary education }(11 / 12) ; \\
\text { make great strides }(10 / 12)\end{array}$ \\
\hline The least used & make good on $(2 / 12)$ \\
\hline
\end{tabular}

The use of target vocabulary by student is represented in Table 3.

Table 3

Target Vocabulary Usage/ Recall by Student

\begin{tabular}{|l|c|c|c|l|l|c|c|}
\hline \multicolumn{4}{|c|}{ Group 2 } & \multicolumn{4}{c|}{ Group 3 } \\
\hline Student & Essay & Posttest1 & Posttest2 & Student & Pretest & Posttest1 & Posttest 2 \\
\hline St 1 & 5 & 8 & 5 & St1 & 1 (face*) & 9 & 8 \\
\hline St 2 & 8 & 6 & 7 & St 2 & 1 (face) & 8 & 8 \\
\hline St 3 & 6 & 4 & 7 & St 3 & 1 (face) & 9 & 7 \\
\hline St 4 & 4 & 6 & 8 & St 4 & 0 & 7 & 6 \\
\hline St 5 & 3 & 6 & 4 & St 5 & 1 (face) & 6 & 6 \\
\hline St 6 & 9 & 4 & 6 & St 6 & 1 (aim**) & 7 & 5 \\
\hline St 7 & 5 & 10 & 6 & St 7 & 1 (aim) & 6 & 4 \\
\hline St 8 & 0 & 3 & 4 & St 8 & 0 & 6 & 3 \\
\hline St 9 & 4 & 6 & 6 & St 9 & 1 (aim) & 5 & 4 \\
\hline St 10 & 3 & 7 & 5 & St 10 & 0 & 4 & 4 \\
\hline St 11 & 7 & 4 & 7 & St 11 & 0 & 3 & -- \\
\hline St 12 & 10 & 4 & 6 & & & & \\
\hline Average: & $\mathbf{5 . 3 4 / 1 0}$ & $\mathbf{5 . 6 7 / 1 0}$ & $\mathbf{5 . 9 2 / 1 0}$ & Average: & $\mathbf{0 . 6 4 / 1 0}$ & $\mathbf{6 . 3 6 / 1 0}$ & $\mathbf{5 . 5 / 1 0}$ \\
\hline
\end{tabular}

Note: * face stands for "in (the) face of"; **aim = "achieve an aim"

Group 2 on average used 5.34/10 collocations in their essays, demonstrated the average recall rate of 5.67/10 expressions in the earlier posttest, and 5.92/10 recall in the last posttest. The learner gains in the delayed posttest do not seem to correlate with the amount of the target vocabulary in the essay, e.g. the student who did not come up with any target vocabulary items in their essay still managed to remember 4 target 
items, which was even higher than the result in the first test. While the students who used maximum vocabulary ( 9 and 10 items) managed to recall 6 expressions. Meanwhile, the recall rate of Group 3 fell from 6.36 from the first to 5.5/10 in the second posttest.

\section{Discussion}

One of the aims of our study was to see how effectively upper-intermediate university students can identify collocations in an input text. It was observed that both Group 1 and Group 2, asked to identify collocations in the input text without any extra prompts, tended to go for phrasal verbs rather than verb/ adjective + noun constructions. This confirms Boers and Lindstromberg's (2009) doubts about the learners' ability to identify collocations on their own, and a notorious vagueness of the definition of 'collocation' for English as a Foreign Language (EFL) learners.

Initially, it had been planned to conduct the experiment in three groups, with one of them subjected to incidental acquisition. In this group (Group 1) only 6 students out of 14 completed the online test (sentences in Ukrainian featuring the target collocations to be translated into English), which followed the classroom discussion of the target vocabulary. In absolute majority of cases the target collocations failed to be identified. It could seem that the two collocations which were unfamiliar to the students - 'make great strides' and 'make good on' - would have attracted their attention and required extra mental effort to retain, which may have resulted in higher retention rates. However, it was not the case - the items were recalled by only two learners. The most popular collocation turned out to be 'achieve an aim' which was recalled by 5 students out of 6 , the next was 'in (the) face of' - 3 times, and 'tertiary education' (2 times) - all the rest of students stuck to the old favorites like 'higher' or ('high') education. 'Prospective students' were forgotten in favor of 'future' or 'students to be', 'classroom' in favor of 'learning', 'insurmountable obstacle' was replaced by 'unbeatable'. Due to the learners' reluctance and poor results the second part of the experiment in their group had to be cancelled, while the few results obtained in the first test turned the incidental uptake research into unrepresentative.

Another objective of the study was to assess the accuracy of the target lexis usage in the students' written output: eleven students out of Group 2's 13 used at least 
one target collocation in their essays, the most popular being 'tertiary education' and 'make (great) strides in', which could be explained by the relevance of this vocabulary for the subject of the essay, and the students' desire to practice the collocation that was new to them. Other popular expressions included: 'in dire need', 'prospective students', 'traditional classroom features', 'in (the) face of'. The least used multi-word unit turned out to be the collocation 'make good on' which had most probably been unknown to the learners before they read the article and which the context did not readily call for. The expressions used mostly incorrectly were 'make great strides' and 'make good on', which was quite foreseeable as they were unfamiliar to the students, and their idiomatic component turned their correct use into a challenge, as well as 'in the face of', a close equivalent of the learners' L1 idiom, which had seemed unlikely to pose difficulties.

Sample incorrect usage of target collocations can be found in the following extracts from the learners' essays:

- "people have made great strides in advances in technology": pleonasm, as the collocation means 'advances';

- "in the face of almost two months of self-isolation, we need to improve methods...": it sounds like these two months will come in future, although in fact they had been over at the moment of essay writing. The author most probably meant "based on";

- "a large number of self-study tasks [...], making good on which is also a difficult challenge": the student obviously confused the meaning of the collocation with 'performing well on a task'.

Another frequently misused item was 'traditional classroom features', in which classroom -despite explicit discussion in the lesson - was not viewed as a metonymy, a synonym to 'learning', but in its more familiar meaning of 'premises where studying occurs': "Traditional classroom education features form social skills" or in: "traditional features of seminars and classrooms", where 'classroom' is wrongly used as a synonym for 'a lecture'.

In the first posttest in Group 2 one of the worst remembered items turned out to be 'make good on' - recalled by only $50 \%$ of the students, which was only surpassed by 'insurmountable obstacle' and 'traditional classroom features' (34\% recall rate each). 
The former posed problems recalling the correct adjective, while in the latter 'classroom' was commonly replaced by 'educational' features, which corresponds to the adjective with the same meaning in the learners' L1. The most well remembered items were 'dire need', 'in face of', 'achieve an aim', 'make strides' with 75\% retention rate each. At the same time, there was no direct correlation between these recall rates and the usage of the items in the students' essays: it ranged from 34\% ('in face of') to $75 \%$ ('make strides').

The Group 2 immediate and delayed posttests showed different learning gains for different items: two items were recalled by $75 \%$ of the learners in both tests; four items increased recall rate in the second posttest; and other four decreased, including 'make great strides' and 'make good on'. The overall recall rate in Group 2 slightly increased - from 5.67 to 5.92 items. The most well remembered item was 'prospective student' (92\%), although it had not been frequently used in the essays (58\%), 'dire need', 'in face of', 'achieve an aim', 'tertiary education' all showed consistently high recall rates in both Group 2 posttests. Something unexpected was the idiom 'make great strides in' which was one of the students' top used expressions in essay writing, had a high recall rate in the first posttest, but after a month was retained by only half of the group, with only four students able to recall its full form with the adjective 'great'. Incidentally, the idiom was among the worst recalled for Group 3 as well. The only student who was close to the reproduction of its form came up with 'make a great strides', other two remembered 'make strides' with the right adjective missing. The other three collocations with $75 \%$ recall rate in the first posttest showed approximately the same retention rates after a month.

As for the impact of the written output on the final learning outcomes, unlike the results demonstrated by the single word recall experiment by Nguyen and Boers (2018), where the output group demonstrated a twice better learning rate, the present study Group 2 subjected to written output did not come up with radically better results compared to Group 3, who did not write essays: nearly 6 items out of ten remembered by Group 2 in the delayed posttest, vs 5.5 items recalled by Group 3. Meanwhile, there is no consistent correlation between the recall rate of certain items by the Group 2 students in the delayed posttest and their usage in the essays. In other words, although 'in face of' was among the least used items (34\%), it then was recalled 
by $75 \%$ of the learners in the delayed posttest, or 'make strides' used by $75 \%$ of the learners in their essays and later recalled by only half of the group. A more or less consistent result however is demonstrated here by the unfamiliar 'make good on' the lowest usage in the essays (17\%) and one of the lowest recall rates $(42 \%)$ in the delayed posttest, testifying to the importance of the prior (at least passive) awareness of the meaning and the form of the collocation.

Against this background it is worth looking at the results of the no-output Group 3: although their final score was only slightly lower than Group 2's (Group 2's 5.92 vs Group 3's 5.5), in fact it dropped from 6.36 in their first posttest: while three learners managed to come up in the delayed posttest with the same results as in the first one, the rest of the students performed worse, forgetting from one to three expressions in the course of four weeks. Unlike Group 3, Group 2 demonstrated a tendency to improving their gains. It could be therefore assumed that in a longer perspective Group 3's recall rate might continue decreasing, while Group 2's prospects appear more hopeful. The learning outcomes attested in this research (55-59\% of the target lexis retained in productive recall) are somewhat higher than the results cited in Pauwels (2018) for single words recall rate. Generally, it could be concluded that although the written output did not seem to dramatically increase the group's recall rate, it is still likely to have benefitted retention in a long-term perspective. These findings may suggest a higher effectiveness of the actual need, which motivated the Group 2 students to find collocations they would like to use in texts of their own, combined with the evaluation component, compared to the 'artificial' need, when learners had to find collocations in the article stimulated by their first translation task.

The items best remembered by the groups 2 and 3 were 'in face of' $(75 \%$ and $100 \%$ recall respectively), and 'prospective students' (92\% and $90 \%$ ), which could be explained by the closeness of the form and meaning of the collocation to corresponding lexical items in learners' L1. These observations are in contrast with the fact that the Group 3 learners were rather poor at recalling the collocation 'achieve an aim', equivalent to their L1 phrase, whose meaning the learners had definitely known prior to the experiment. The reason behind it could be the students' awareness of other synonyms of the verb 'to achieve', e.g. to reach a goal which rather did 
learners a disservice in this case. Similarly to Group 2, the worst recalled items were 'make great strides in' and 'make good on', whose form and meaning had been unfamiliar to the learners before the test. Overall, the results of the present research correlate with the findings attested by the research by Puimege and Peters (2020), which suggested that the learners' pre-knowledge of the meaning of formulaic sentences was the strongest predictor of their learning gains.

The experiment revealed unexpected psychological implications connected with the unconventional online mode of instruction. First-year students of the Faculty of Philosophy appeared quite reluctant to participate in the research; as a result, the initial plan of the study had to be altered accordingly. Under normal conditions of study, before the lockdown set in, the learners had acted responsively in class, so the change in our rapport came as a surprise. At the same time, the other two groups took an active part in the experiment, although for the third-year group the participation was conducted on a good will basis.

\section{Limitations}

As any classroom-based experiment, the present study has temporal limitations. Learners' recall rate can only be assessed over a certain time span, which correlates with a course duration. This makes it impossible to attest the students' longer-term learning gains, unless the teacher is lucky enough to teach the same group over longer spans of time. So, in the case of this experiment, it remains a question how durable the attested results are, if with time the learners' uptake will turn into receptive recognition, or the learners will manage to keep the items in productive usage. It is also impossible to analyse with a large degree of objectivity the amount of learners' productive use of the target lexis, as the teacher fails to hear $100 \%$ of the students' spoken output even in the regular classroom, not to mention online classroom chat rooms or the learners' engagement with L2 outside of the classroom. Therefore, only productive form recall could be attested more or less objectively.

Another limitation is related to the mode of conducting the study. Because all the posttests had to be run online, it was impossible to see how diligent the learners were while doing them. 


\section{Conclusions}

The productive collocational competence is crucial for English language learners to become fluent and instrumental in their use of L2 in various contexts, including the academic environment. The implications of the present study for the classroom indicate that the most challenging type of collocations are those which have nothing in common form or meaning - with the students' L1 and that the most effective way of acquiring the collocational form-meaning link is intentional learning with the possibility of using the target items in a productive output. EFL and ESP university syllabuses should accommodate activities aimed at explicit teaching and further revisiting of collocational vocabulary in communicative classes, which traditionally favor meaning-oriented tasks instead of intentional memorizing of vocabulary lists. Another indispensable condition of internalizing collocations is regular recycling, which should feature in corresponding lesson planning and appears feasible in university context, which offers regular L2 instruction in groups with consistent participants.

The experiment was conducted under the online mode of learning, new for the ESP university environment, which calls for further investigation of effective strategies applicable under such studying conditions, given a major shift to online learning due to the current circumstances.

\section{References}

Adamcova, S. (2020). Empirical research of collocations in foreign language learning. Advanced Education, 14, 75-83. https://doi.org/10.20535/2410-8286.197363

Boers, F., \& Lindstromberg, S. (2009). Optimizing a lexical approach to instructed second language acquisition. Palgrave Macmillan. https://doi.org/10.1057/9780230245006

Boers, F., \& Lindstromberg, S. (2012). Experimental and intervention studies on formulaic sequences in a second language. Annual Review of Applied Linguistics, 32, 83-110. https://doi.org/10.1017/S0267190512000050

Carter, R., \& Nunan, D. (2002). The Cambridge guide to teaching English to speakers of other languages. Cambridge University Press. https://doi.org/10.1017/CB09780511667206

Durrant, P. (2014). Corpus frequency and second language learners' knowledge of collocations. A meta-analysis. International Journal of Corpus Linguistics, 19(4), 443-477. https://doi.org/10.1075/ijcl.19.4.01dur 
Ellis, R. (1999). Learning a second language through interaction. John Benjamins. https://doi.org/10.1075/sibil.17

Ellis, N. C. (2003). Constructions, chunking, and connectionism: The emergence of second language structure. Revised chapter for Doughty \& Long (Eds.) Handbook of Second Language Acquisition. Blackwell. https://doi.org/10.1002/9780470756492.ch4

Ellis, N. C. (2005). At the interface: Dynamic interactions of explicit and implicit language knowledge. Studies in Second Language Acquisition, 27, 305-352. https://doi.org/10.1017/S027226310505014X

Ellis, N. C., Simpson-Vlach, R., \& Maynard, C. (2008). Formulaic language in native and second language speakers: Psycholinguistics, corpus linguistics and TESOL. TESOL Quarterly, 42, 375-396. https://doi.org/10.1002/i.15457249.2008.tb00137.x

Firth, J. (1968). A Synopsis of Linguistic Theory 1930-1955. In Palmer, F.R. (Ed.). Selected Papers of J.R. Firth 1952-59: (pp. 1-32). Indiana University Press.

Fitzpatrick, T., Al-Quarni, I. \& Meara, P. (2008). Intensive vocabulary learning: a case study, Language Learning Journal, 36, 2, 116-132. https://doi.org/10.1080/09571730802390759

Garnier, M., \& Schmitt, M. (2016). Picking Up polysemous phrasal verbs: How many do learners know and what facilitates this knowledge? SYSTEM, 59, 29-44. https://doi.org/10.1016/i.system.2016.04.004

González Fernández, B. \& Schmitt, N. (2015). How much collocation knowledge do L2 learners have? The effects of frequency and amount of exposure. ITL International Journal of Applied Linguistics, 166, 94-126. https://doi.org/10.1075/itl.166.1.03fer

Hoey, M. (2012). Lexical Priming. In Carol A. Chapelle (Ed.), The Encyclopaedia of Applied Linguistics. Blackwell Publishing https://doi.org/10.1002/9781405198431.wbeal0694

Krashen, S. (2009). Principles and Practice in Second Language Acquisition (1 ${ }^{\text {st }}$ Internet Edition).

Laufer, B. (2005). Focus on Form in Second Language Vocabulary Learning. EUROSLA (Ed.), EUROSLA Yearbook 5, 223-250. John Benjamins Publishing. https://doi.org/10.1075/eurosla.5.11lau

Laufer, B. \& Rozovski-Roitblatt, B. (2011). Incidental vocabulary acquisition: The effects of task type, word occurrence and their combination. Language Teaching Research, 15 (4), 391-411. https://doi.org/10.1177/1362168811412019 
Laufer, B., \& Hulstijn, J. H. (2001). Incidental vocabulary acquisition in a second language: The construct of task-induced involvement. Applied Linguistics, 22, 126. https://doi.org/10.1093/applin/22.1.1

Lee, S., \& Pulido, D. (2017). The impact of topic interest, L2 proficiency, and gender on EFL incidental vocabulary acquisition through reading. Language Teaching Research, 21, 118-135. https://doi.org/10.1177/1362168816637381

Lewis, M. (1999). The Lexical Approach: The State of ELT and A Way Forward. Language Teaching Publications.

Lewis, M. (2000). Teaching collocation: Further developments in the lexical approach. Language Teaching Publications.

Macis, M. \& Schmitt, N. (2017). Not just 'Small Potatoes': Knowledge of the idiomatic meanings of collocations. Language Teaching Research, 21(3), 321-340. https://doi.org/10.1177/1362168816645957

Nguyen, C. D., \& Boers, F. (2018). The Effect of Content Retelling on Vocabulary Uptake from a TED Talk. TESOL Quarterly, 52(1), 1-25. http://dx.doi/abs/10.1002/tesq.441

Pauwels, P. (2018). How advanced students approach intentional vocabulary study. The Language Learning Journal, 46(3), 293-310. https://doi.org/10.1080/09571736.2015.1078398

Pellicer-Sánchez, A. (2017). Learning L2 collocations incidentally from reading. Language Teaching Research, 21(3), 381-402. https://doi.org/10.1177/1362168815618428

Peters, E. (2014). The effects of repetition and time of post-test administration on EFL learners' form recall of single words and collocations. Language Teaching Research, 18(1), 75-94. https://doi.org/10.1177/1362168813505384

Peters, E. (2016). The learning burden of collocations: The role of interlexical and intralexical factors. Language Teaching Research, 20(1), 113-138. https://doi.org/10.1177/1362168814568131

Puimège, E., \& Peters, E. (2020). Learning formulaic sequences through viewing L2 television and factors that affect learning. Studies in Second Language Acquisition, 42(3), 525-549. https://doi.org/10.1017/S027226311900055X

Reuterskiöld C, \& Van Lancker Sidtis, D. (2012). Retention of idioms following one-time exposure. Child Language Teaching and Therapy, 29(2), 216-228. https://doi.org/10.1177/0265659012456859

Schmitt, N. (2008). Instructed Second Language Vocabulary Learning. Language Teaching Research, 12(3), 329-363. https://doi.org/10.1177/1362168808089921 
Sinclair, J. (1991). Corpus, Concordance, Collocation. Oxford University Press.

Snoder, P. (2017). Improving English Learners' Productive Collocation Knowledge: The Effects of Involvement Load, Spacing, and Intentionality. TESL Canada Journal, 34(3), 140-164. https://doi.org/10.18806/tesl.v34i3.1277

Szudarski, P. (2017). Learning and teaching L2 collocations: insights from research. TESL Canada Journal, 34(3), 205-216. https://doi.org/10.18806/tesl.v34i3.1280

Wray, A. (2002). Formulaic language and the lexicon. Cambridge University Press. https://doi.org/10.1017/CB09780511519772 